\title{
Влияние импульсных скользящих поверхностных разрядов на сверхзвуковое обтекание тонкого клина в ударной трубе
}

\author{
(C) И.В. Мурсенкова, А.С. Сазонов, Ю. Ляо
}

Московский государственный университет им. М.В. Ломоносова, Москва, Россия

E-mail: murs_i@physics.msu.ru

Поступило в Редакцию 11 октября 2017 г.

Проведено экспериментальное исследование влияния импульсных скользящих поверхностных разрядов длительностью $\sim 300 \mathrm{~ns}$ на обтекание тонкого клина сверхзвуковым потоком воздуха с числом Маха $1.2-1.5$ в ударной трубе при плотности $0.12-0.14 \mathrm{~kg} / \mathrm{m}^{3}$. Обнаружено, что неоднородность поля плотности течения около клина приводит к изменению геометрии протекания тока и структуры свечения поверхностных разрядов. Теневым методом исследована динамика ударных волн, инициированных разрядами, движение которых возмущает квазистационарное сверхзвуковое обтекание клина. Показано, что ударные волны от интенсивных каналов поверхностного разряда перед носом клина и за его донной частью могут оказывать нестационарное воздействие на обтекаемую поверхность продолжительностью до $120 \mu$ s после разряда.

DOI: 10.21883/PJTF.2018.04.45639.17074

Модификация поля течения при помощи плазменных актуаторов может приводить к изменению характеристик обтекания тел высокоскоростными потоками в результате взаимодействия плазмы с газовой средой [1-5]. В исследовательских задачах сверхзвуковой плазменной газодинамики такие устройства представляют значительный интерес изза ряда преимуществ, в частности их быстродействия и возможности оптимального расположения на обтекаемой поверхности $[1,3,5]$. Целью настоящей работы является экспериментальное исследование влияния скользящих поверхностных разрядов наносекундной длительности на обтекание тонкого клина в ударной трубе сверхзвуковым потоком 


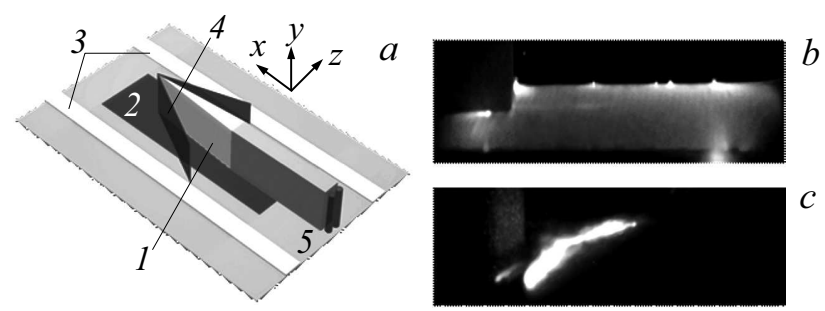

Рис. 1. $a-$ схема течения около клина в разрядной камере: $1-$ клин, 2 - область разряда, 3 - положение кварцевых стекол, 4 - головная ударная волна, 5 - вихревая область; $b, c-$ фотоизображения свечения поверхностного разряда на нижней стенке разрядной камеры в неподвижном воздухе $(b)$ и в вихревой области за клином в сверхзвуковом потоке с числом Маха 1.27 при плотности $0.12 \mathrm{~kg} / \mathrm{m}^{3}(c)$. Поток направлен слева направо. Слева видна донная стенка клина. Изображение на части $c$ зарегистрировано через светофильтр, пропускающий излучение с длиной волны $405 \mathrm{~nm}$.

воздуха с числом Маха $1.2-1.5$, а также ударно-волновых процессов после разряда.

Исследование проводилось на установке, представляющей собой ударную трубу с разрядной камерой с каналом прямоугольного сечения $24 \times 48 \mathrm{~mm}[3,6]$. Две боковые стенки канала разрядной камеры выполнены из плоскопараллельных кварцевых стекол, на верхней и нижней стенках расположены плоские системы электродов поверхностных разрядов (рис. $1, a$ ). Рабочим газом являлся воздух при давлении $2.7-53.3 \mathrm{kPa}$. Сверхзвуковые потоки со скоростью $630-950 \mathrm{~m} / \mathrm{s}$ создавались за плоскими ударными волнами с числами Маха 2.6-3.6. При таких условиях в разрядной камере реализовалось однородное сверхзвуковое спутное течение с числом Маха $1.2-1.5$ длительностью $300-500 \mu \mathrm{s}$ (замыкающееся контактной поверхностью) [7,8]. Тонкий клин из диэлектрика (капролона) высотой $24 \mathrm{~mm}$, длиной $49 \mathrm{~mm}$ и шириной $8 \mathrm{~mm}$ с углом раствора $\sim 9^{\circ}$ устанавливался в разрядной камере навстречу плоской ударной волне под нулевым углом атаки к потоку за ней. После дифракции ударной волны на клине в течение $\sim 100 \mu \mathrm{s}$ устанавливалось его стационарное сверхзвуковое обтекание с клиновидной головной ударной волной $[8]$ длительностью $\sim 200-400 \mu \mathrm{s}$. На этой стадии течения в экспериментах инициировались протяженные

Письма в ЖТФ, 2018, том 44, вып. 4 
поверхностные разряды площадью $100 \times 30 \mathrm{~mm}$ на верхней и нижней стенках канала разрядной камеры (рис. 1,a).

Импульсный скользящий поверхностный разряд развивается в тонком газовом слое вблизи поверхности диэлектрика при подаче импульсного напряжения на систему электродов специальной конфигурации и может применяться в качестве плазменного актуатора $[2,3,6,7]$. Прикладываемый импульс напряжения с крутизной нарастания $\sim 10^{11} \mathrm{~V} / \mathrm{s}$ имел амплитуду $16-25 \mathrm{kV}$, сила тока составляла $\sim 1 \mathrm{kA}$, длительность $\sim 300$ ns. Приведенное электрическое поле достигало значений $E / N \sim 10^{-19} \mathrm{~V} \cdot \mathrm{m}^{2}(E-$ напряженность электрического поля, $N$ - концентрация молекул). В неподвижном воздухе при плотности $0.12-0.14 \mathrm{~kg} / \mathrm{m}^{3}$ разряд состоит из параллельных прямолинейных каналов, скользящих по поверхности диэлектрика и образующих однородный плазменный слой (плазменный лист) толщиной менее $0.5 \mathrm{~mm}[6,7]$. От каналов разряда образуются полуцилиндрические ударные волны, которые взаимодействуют друг с другом. Присутствие клина в плоскости разрядов приводило к перекрытию некоторой области разрядных каналов, однако в оставшейся части плазменный слой в неподвижном воздухе оставался однородным (рис. 1,b). В сверхзвуковых потоках при числах Рейнольдса $\sim 10^{5}$ толщина плазменного слоя соизмерима с толщиной пограничного слоя на стенках канала разрядной камеры, и особенности течения около поверхности влияют на характер и геометрию развития каналов поверхностного скользящего разряда [7].

В экспериментах теневым методом исследовались поле течения около клина от момента прихода плоской ударной волны к носу клина до окончания однородного спутного течения и динамика движения ударно-волновых конфигураций в течение 200-400 $\mu$ s после разряда. Оптическая система теневого зондирования формировала параллельный оптический пучок диаметром $40 \mathrm{~mm}$ и направляла его перпендикулярно стеклам разрядной камеры. Теневые изображения регистрировались высокоскоростной камерой Photron Fastcam SA5 с частотой до 150000 кадров в секунду, временем экспозиции $1 \mu \mathrm{s}$. Одновременно регистрировались фотоизображения свечения разрядов через стекла разрядной камеры фотокамерами Canon EOS 550D и Nikon D50, расположенными под небольшим углом к плоскости плазменных листов. Так как длительность свечения разряда менее $500 \mathrm{~ns}$, фотоизображения давали мгновенную с точки зрения газодинамики картину распределения излучения поверхностных разрядов. Синхронизация процессов в экспериментах

Письма в ЖТФ, 2018, том 44, вып. 4 


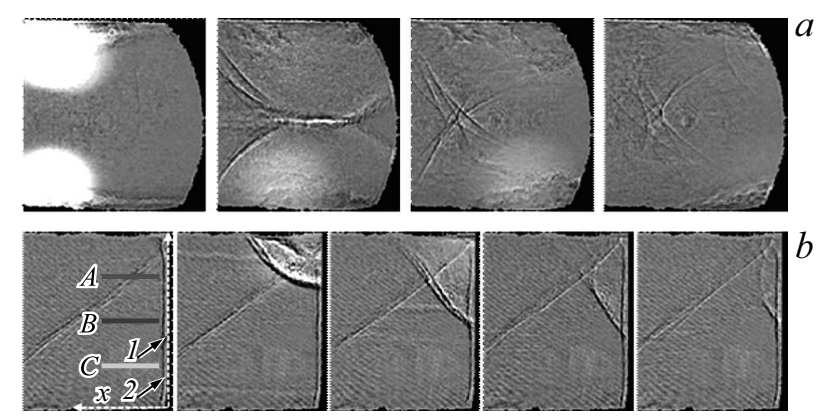

Pис. 2. Последовательности теневых изображений поля течения после разряда. $a$ - за донной частью клина при условиях эксперимента, соответствующих рис. $1, c$. Яркие области на первом кадре показывают свечение каналов разряда. Левая граница кадров совпадает с плоскостью донной части клина. Время между кадрами $7 \mu \mathrm{s}$, экспозиция $1 \mu \mathrm{s}$. $b-$ перед носом клина в сверхзвуковом потоке с числом Маха 1.44 при плотности $0.14 \mathrm{~kg} / \mathrm{m}^{3}$. Темная линия на правой границе кадров совпадает с носом клина (1), полоса слева от нее - фронт головной ударной волны (2). Время между кадрами $9 \mu \mathrm{s}$, экспозиция $1 \mu \mathrm{s}$. Поток направлен слева направо; буквами обозначены линии, соответствующие сечениям течения в канале $y=18(A), 12(B), 6 \mathrm{~mm}(C)$.

и запуск регистрирующей аппаратуры осуществлялись с помощью сигналов от пьезоэлектрических датчиков давления в канале ударной трубы.

Было проведено две серии экспериментов: в первой серии клин располагался симметрично в центре разрядной области; во второй серии экспериментов клин был удлинен вставкой так, чтобы донная часть клина располагалась вне разрядной области (рис. 1, $a$ ). Во втором случае изучалось влияние поверхностных разрядов на течение перед носовой частью клина. Вставка из капролона имела форму прямоугольного параллелепипеда высотой $24 \mathrm{~mm}$, длиной $52 \mathrm{~mm}$ и шириной $8 \mathrm{~mm}$. При стационарном сверхзвуковом обтекании клина в канале поле течения содержит клиновидную головную ударную волну перед носом клина, отраженные от стенок канала ударные волны, косые скачки уплотнения и вихревую область с пониженной плотностью за донной частью клина (рис. $1 a$ ). Масштаб вихревой области порядка ширины донной части клина в поперечном к потоку направлении.

Письма в ЖТФ, 2018, том 44, вып. 4 


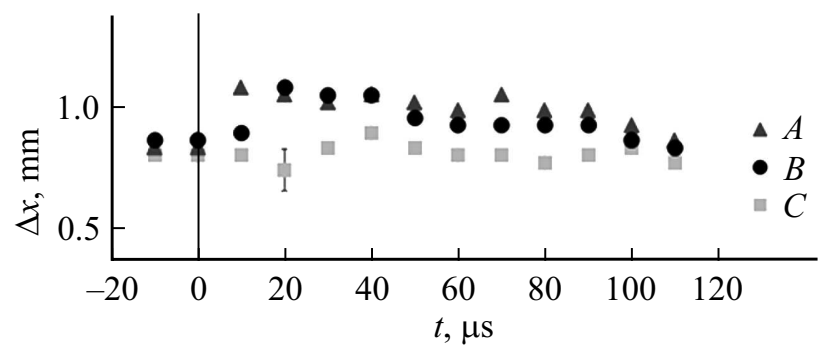

Рис. 3. Временнб́е зависимости среднего отхода головной ударной волны в сечениях течения $y=18(A), 12(B), 6 \mathrm{~mm}(C)$ (указаны на первом кадре pис. $2, b), t=0$ соответствует моменту разряда.

Развитие импульсного разряда в неоднородном поле плотности происходит таким образом, что пробой инициируется в области максимальных значений приведенного электрического поля $E / N[7,9,10]$. Регистрация свечения разрядов в первой серии экспериментов показала, что поверхностные разряды развиваются только в вихревой области пониженной плотности на расстоянии $6-9 \mathrm{~mm}$ от донной части клина в виде одного или нескольких криволинейных каналов повышенной интенсивности (рис. 1,c) симметрично на верхнем и нижнем плазменных листах. Свечение образующихся каналов разряда неоднородно по длине: в средней области интенсивность свечения ниже, чем на краях, и центральная часть канала изогнута в сторону клина. Таким образом, происходит перераспределение энерговклада в газ как по поверхности, так по длине образовавшегося разрядного канала. Теневые изображения поля течения после разряда показали, что в этом случае от верхнего и нижнего каналов разряда образуются интенсивные ударные волны, имеющие скорость до $1500 \mathrm{~m} / \mathrm{s}$ на начальной стадии движения (рис. 2,a). Они движутся симметрично навстречу друг другу, взаимодействуют друг с другом и оказывают воздействие на донную часть клина в течение 30-40 $\mu$ s после разряда. Форма фронтов ударных волн отлична от полуцилиндрической; образовавшаяся ударно-волновая конфигурация перемещается со скоростью, близкой к скорости потока.

Во второй серии экспериментов исследовалось свечение разрядов и поле течения перед носом клина после инициирования разрядов. В проведенных экспериментах свечение поверхностных разрядов было

Письма в ЖТФ, 2018, том 44, вып. 4 
неоднородным. На квазистационарной стадии обтекания перед клином находился, как правило, единственный интенсивный разрядный канал, положение которого было различным при разных условиях. От канала разряда формировалась сильная ударная волна, которая двигалась в потоке, набегающем на клин, и существенно влияла на течение перед носом клина. Набор теневых изображений на рис. 2, $b$ показывает, как ударная волна от канала разряда верхнего плазменного листа движется сверху вниз, затухая со временем и перемещаясь с потоком направо (3-5 кадры, 10-40 $\mu$ s после разряда). Эта ударная волна и поток за ней взаимодействуют с головной ударной волной перед клином, приводя к изменению ее формы и положения и, следовательно, к изменению режима обтекания.

Анализ полученных теневых изображений показал динамику отхода головной ударной волны (расстояние от носа клина до фронта ударной волны) (рис. 3). На рис. 2, $b$ указаны сечения течения в канале (обозначенные линиями $A, B, C$ ), вдоль которых проводилась обработка изображений и измерялся отход головной ударной волны от носа клина. Невозмущенное стационарное значение отхода головной ударной волны при числе Маха потока $1.43 \pm 0.03$ составляло $0.85 \pm 0.05 \mathrm{~mm}$ при плотности $0.14 \mathrm{~kg} / \mathrm{m}^{3}$. Взаимодействие головной ударной волны с ударной волной от канала разряда приводило к локальному увеличению отхода, а затем в течение 70-120 $\mu$ s возвращению к стационарному невозмущенному значению. Среднее по серии экспериментов значение отхода головной ударной волны после разряда превышало невозмущенное значение на $25 \pm 5 \%$ и оставалось увеличенным в течение $\sim 70 \mu \mathrm{s}$ вдоль линии $A$ и в течение $\sim 40 \mu$ s вдоль линии $B$ (рис. 3 ).

Таким образом, проведенное исследование показало, что инициирование скользящих поверхностных разрядов вблизи обтекаемого сверхзвуковым потоком воздуха тонкого клина (число Маха потока 1.2-1.5) приводит к изменению геометрии протекания тока разрядов и изменению поля течения после разряда. Свечение плазмы скользящего разряда в сверхзвуковом потоке за препятствием локализуется в криволинейный неоднородно излучающий канал, положение которого зависит от геометрии вихревой области. Показано, что ударные волны от интенсивных разрядных каналов могут оказывать продолжительное воздействие на донную часть клина и на головную ударную волну перед клином, вызывая ее нестационарное смещение. На основе высокоскоростной теневой съемки установлено, что продолжительность нестационарного

Письма в ЖТФ, 2018, том 44, вып. 4 
воздействия локализованного энергоподвода значительно превышает длительность разряда и может продолжаться до $120 \mu$ s после разряда.

Работа выполнена при частичной поддержке гранта РФФИ 17-0800560.

\section{Список литературы}

[1] Wang J.J., Choi K., Feng L., Jukes T.N., Whalley R.D. // Progr. Aerospace Sci. 2013. V. 62. P. 52-78.

[2] Bayoda K.D., Benard N., Moreau E. // J. Appl. Phys. 2015. V. 118. N 6. P. 063301.

[3] Знаменская И.А., Латфуллин Д.Ф., Луцкий А.Е., Мурсенкова Т.В. // Письма в ЖТФ. 2010. Т. 36. В. 17. С. 35-41.

[4] Желтоводов А.А., Пимонов Е.А. // ЖТФ. 2013. Т. 83. В. 2. С. 21-35.

[5] Лапушкина Т.А., Ерофеев А.В., Поняев С.А. // ЖТФ. 2011. Т. 81. В. 5. С. 28 34.

[6] Знаменская И.А., Латфуллин Д.Ф., Луцкий А.Е., Мурсенкова И.В., Сысоев Н.Н. // ЖТФ. 2007. Т. 77. В. 5. С. 10-18.

[7] Belysheva I., Mursenkova I., Chvyreva A. // J. Phys.: Conf. Ser. 2014. V. 516. N 1. P. 012021.

[8] Бажсенова Т.В., Гвоздева Л.Г. Нестационарные взаимодействия ударных волн. М.: Наука, 1977. 274 с.

[9] Райзер Ю.П. Физика газового разряда. М.: Наука, 1987. 592 с.

[10] Знаменская И.А., Иванов И.Э., Кулькин М.К., Мурсенкова И.В., Сазонов А.C. // Сб. тез. докл. XLIV Междунар. Звенигород. конф. по физике плазмы и УТС. М., 2017. С. 278.

5 Письма в ЖТФ, 2018, том 44, вып. 4 